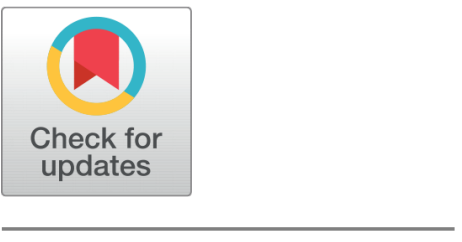

OPEN ACCESS

Received: 18.11.2020

Accepted: 20.01.2021

Published: 02.02 .2021

Citation: Matti S, Shivakumar BP, Shashidhar S, Nagaral M (2021) Dry sliding wear behavior of Mica, Fly Ash and Red Mud particles reinforced Al7075 alloy hybrid metal matrix composites. Indian Journal of Science and Technology 14(4): 310-318. https://doi.org/ 10.17485/IJST/v14i4.2081

* Corresponding author.

Tel: +91 7259249015

sgmatti@gmail.com

Funding: None

Competing Interests: None

Copyright: (c) 2021 Matti et al. This is an open access article distributed under the terms of the Creative Commons Attribution License, which permits unrestricted use, distribution, and reproduction in any medium, provided the original author and source are credited.

Published By Indian Society for Education and Environment (iSee)

ISSN

Print: 0974-6846

Electronic: 0974-5645

\section{Dry sliding wear behavior of Mica, Fly Ash and Red Mud particles reinforced Al7075 alloy hybrid metal matrix composites}

\author{
Siddesh Matti ${ }^{*}$, B P Shivakumar ${ }^{1}$, S Shashidhar ${ }^{2}$, Madeva Nagaral ${ }^{3}$ \\ 1 Department of Mechanical Engineering, JSS Academy of Technical Education, Bangalore, \\ Karnataka, India. Tel.: +91 7259249015 \\ 2 Department of Mechanical Engineering, UVCE, Bangalore, Karnataka, India \\ 3 Aircraft Research and Design Centre, HAL, Bangalore, Karnataka, India
}

\section{Abstract}

Objective: To synthesize and evaluation of wear behavior of mica. The effect of mica, fly ash and red mud particles reinforced Al7075 alloy composites. Method: The hybrid composites were prepared with constant $1 \mathrm{wt} . \%$ of red mud particles and varying weight percentages of mica $(2,4$ and 6 wt. \%) and fly ash (1, 3 and 5 wt. \%) particles in Al7075 alloy by stir casting method. Findings: The synthesized multiple particles reinforced Al7075 alloy hybrid composites were subjected to microstructural studies and wear properties testing. Microstructural characterizations of obtained samples were carried out by scanning electron microscopy and XRD patterns. The mica, fly ash and red mud particles were evenly distributed and presences of these particles were confirmed by the XRD patterns. Novelty /Improvement: Al7075 alloy with red mud, fly ash and mica particles reinforced hybrid composites were exhibited the superior wear resistance. Various wear mechanisms were observed in the Al7075 alloy with mica, fly ash and red mud composites using SEM.

Keywords: Al7075 Alloy; Mica; Fly Ash; Red Mud; Wear; Worn Morphology

\section{Introduction}

Composite materials are materials that contain continuous constituent phase called matrix that holds together and forms stronger, stiffer reinforcement constituent ${ }^{(1,2)}$ resulting in a material with perfect blend of structural properties far better than its constituent parts alone. Combination of properties that make composites superior over conventional structural materials are good design flexibility, high specific strength and specific modulus, high fatigue endurance limit, corrosion and wear resistance, thermal cycling tolerance, tolerable coefficient of thermal expansion ${ }^{(3,4)}$, etc. Relative amount and properties of constituent phases, geometry of dispersed phase including particle size, shape, and orientation in the matrix directs properties of composites ${ }^{(5-7)}$. There are several fabrication techniques available to process composites. The prepared composites are usually evaluated for enhanced properties by conducting experiments like hardness, tensile, compression, fatigue, and tribological tests as per ASTM standards ${ }^{(8,9)}$. 
Due to their low density and reasonable strength, aluminium and its alloys have found applications in many areas. They are currently being used in making of small household applications like foil, beverage cans, food utensils to large applications like making structural parts of commercial and military aircrafts. However, for certain engineering applications, aluminium alloys cannot be used due to their lower strength and poor tribological characteristics ${ }^{(10,11)}$. Keeping an eye on environmental regulations and cost savings, design engineers are looking into novel materials which are light in weight and provide multifunctional properties at reasonable cost. This has led to development of novel alloys and their composites based on light weight metals like aluminium. It is well known that there are many techniques following which one can improve the mechanical, physical and tribological properties of monolithic aluminium or its alloys. The property enhancement can be achieved by addition of second phase particles, heat treatment or subjecting them to secondary processing techniques. Careful observations of these reinforcements tell that most of them have high hardness, low density and thermal stability. Selection of reinforcements mainly depends upon the type of matrix, processing route and requirement of property for a particular application. For economic applications the discontinuous reinforcements like particles or whiskers are most preferred.

Several researchers have investigated the impact of micro and nano particles on the properties of $\mathrm{Al}$ alloy matrices. Hiremath $^{(12)}$ and co-authors evaluated the effect of reinforcement content on the hardness of LM25 alloy with borosilicate glass particulates. In their study, composites were prepared by suing 3, 6, 9 and $12 \mathrm{wt}$. \% of borosilicate particles in the LM25 alloy matrix. The distribution of these borosilicate glass particulates was identified by using optical microscope micro-graphs. Kim et al. ${ }^{(13)}$ studied the tensile behavior of LM25 alloy and in-situ formed $\mathrm{TiB}_{2}$ composites. The composites of $\mathrm{LM}_{25} 5 \mathrm{TiB} 2$ were fabricated by stir cast method using titanium and boride salts to form the $\mathrm{TiB}_{2}$ particles. The maximum tensile strength obtained in the LM25- $\mathrm{TiB}_{2}$ composites was $165.84 \mathrm{MPa}$. Umanath et al. ${ }^{(14)}$ and is team has worked on wear behaviour of Al6061 with $\mathrm{SiC}-\mathrm{Al}_{2} \mathrm{O}_{3}$ hybrid metal matrix composites, in this work the Al6061-T6 condition material was used as matrix in which $\mathrm{SiC}$ and $\mathrm{Al}_{2} \mathrm{O}_{3}$ were reinforced for the preparation of hybrid composites and to study the wear behavior. The required test specimens which were prepared by using stir casting process were tested as per the ASTM standards. The testing of each experiment was conducted by using pin on disc wear tester. Nikhilesh et al. ${ }^{(15)}$ carried out a review on advanced reinforcements to prepare the hybrid metal composites. In the review article, they mentioned the various advanced organic and inorganic reinforcements to prepare the hybrid composites. Further, a review on tribological behavior of aluminum and magnesium based hybrid metal matrix composites were made by Nikhilesh and co-authors ${ }^{(16)}$. Aluminum (Al) and magnesium (Mg) based hybrid metal matrix composites (HMMCs) having properties like a light in weight, better stiffness, hardness, strength to weight ratio, and wear resistance are the best alternatives and has fulfilled the existing problems in all aspects of engineering and medical applications so far. From the literature it is evident that very minimal work is carried out on multi-phase reinforced composites. Hence, in the current research an attempt has been made to synthesize and evaluate the wear behavior of mica, fly ash and red mud particles reinforced Al7075 alloy composite.

In the light of the above, present work focuses on development of hybrid composite material with improved tribological properties using low cost reinforcements. Keeping this in mind a versatile aluminium alloy, Al7075 is chosen as matrix material while low cost reinforcement likes red mud; fly ash and mica were chosen as constituents of hybrid composite. Further, with different mica, red mud and fly ash weight percentages, the hybrid composites were fabricated by economical stir casting technique. The developed hybrid composites were subjected to microstructural and tribological characterization.

\section{Experimental details}

\subsection{Material used}

The Al7075 alloy was chosen as matrix material owing to its superior mechanical properties and wide applications in industrial sector. The chemical composition of Al7075 is given in the Table 1. Mica, fly ash and red mud having particle size 10 mm size, $10 \mathrm{~mm}$ and $10 \mathrm{~mm}$ respectively were used as reinforcement's respectively fabrication of MMCs as in Figure 1 (a-c).

Table 1. Chemical composition of Al7075 alloy

\begin{tabular}{llllllllll}
\hline Element & $\mathrm{Cu}$ & $\mathrm{Cr}$ & $\mathrm{Mn}$ & $\mathrm{Mg}$ & $\mathrm{Si}$ & $\mathrm{Ti}$ & $\mathrm{Zn}$ & $\mathrm{Fe}$ & $\mathrm{Al}$ \\
\hline Wt. \% & 1.8 & 0.2 & 0.4 & 1.9 & 0.5 & 0.15 & 3.25 & 0.5 & $\mathrm{Balance}$ \\
\hline
\end{tabular}




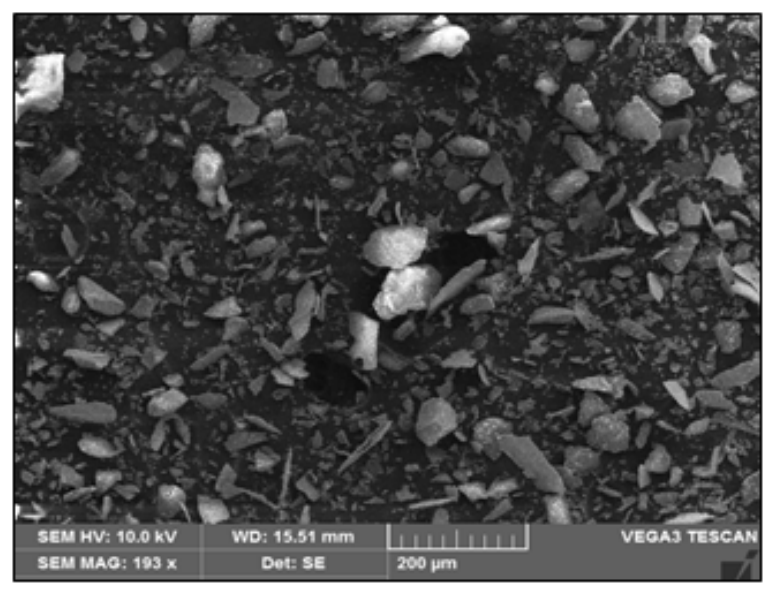

(a)

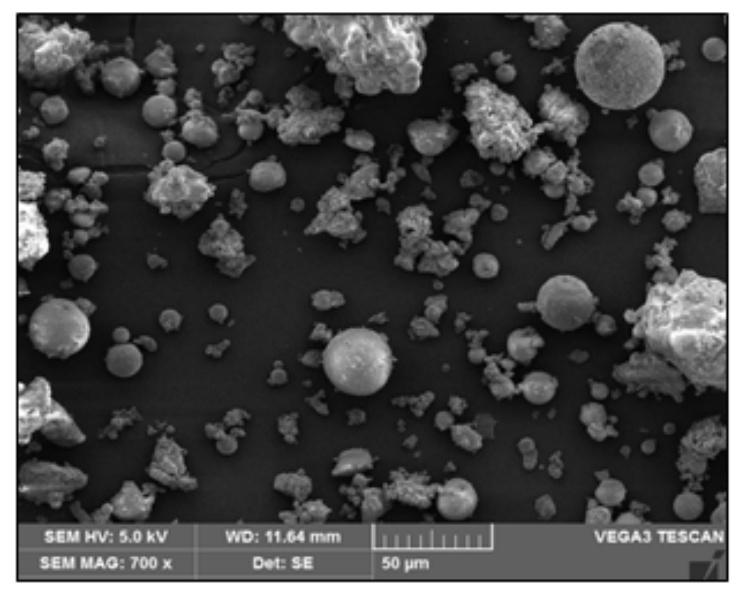

(b)

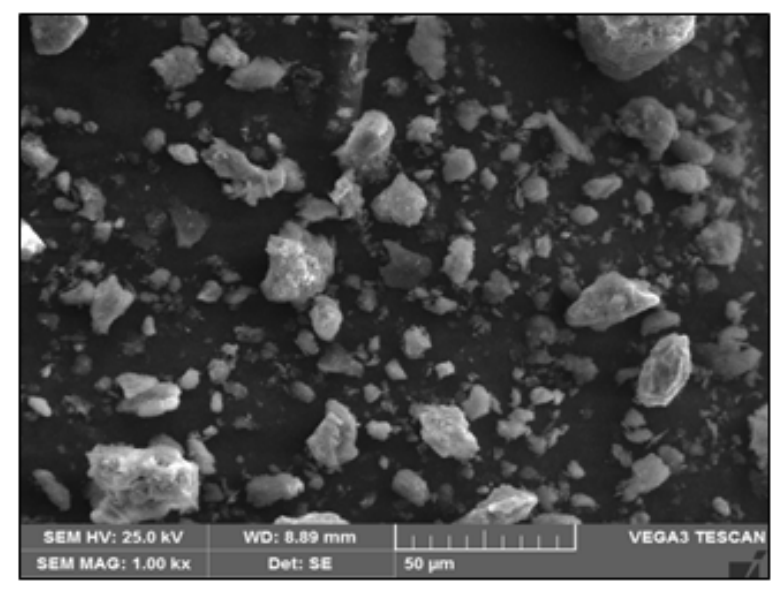

(c)

Fig 1. SEM microphotographs of (a) Mica (b) Fly ash (c) Red mud particles

Table 2. Chemical composition mica particles

\begin{tabular}{ll}
\hline Compounds & Weight Percentage \\
\hline Silica $\left(\mathrm{SiO}_{2}\right)$ & 45.57 \\
Alumina $\left(\mathrm{Al}_{2} \mathrm{O}_{3}\right)$ & 33.10 \\
Potassium $\left.\mathrm{Oxide}_{(\mathrm{K}} \mathrm{O}\right)$ & 9.87 \\
Ferric Oxide $\left(\mathrm{Fe}_{2} \mathrm{O}_{3}\right)$ & 2.48 \\
Sodium Oxide $\left(\mathrm{Na}_{2} \mathrm{O}\right)$ & 0.62 \\
Titanium Oxide $\left(\mathrm{TiO}_{2}\right)$ & Traces \\
Calcium Oxide $(\mathrm{CaO})$ & 0.21 \\
Magnesia $(\mathrm{MgO})$ & 0.38 \\
Moisture at $100^{\circ} \mathrm{C}$ & 0.25 \\
Phosphorus $(\mathrm{P})$ & 0.03 \\
Sulphur $(\mathrm{S})$ & 0.01 \\
Graphite Carbon $(\mathrm{C})$ & 0.44 \\
Loss on Ignition $\left(\mathrm{H}_{2} \mathrm{O}\right)$ & 2.74 \\
\hline
\end{tabular}


Table 3. Chemical composition red mud particles

\begin{tabular}{ll}
\hline Compounds & Weight Percentage \\
\hline $\mathrm{Fe}_{2} \mathrm{O}_{3}$ & 55 \\
$\mathrm{Al}_{2} \mathrm{O}_{3}$ & 15 \\
$\mathrm{SiO}_{2}$ & 20 \\
$\mathrm{Na}_{2} \mathrm{O}$ & 6 \\
$\mathrm{CaO}$ & 3.75 \\
$\mathrm{TiO}_{2}$ & trace-0.25 \\
\hline
\end{tabular}

Table 4. Chemical composition fly ash particles

\begin{tabular}{ll}
\hline Compounds & Weight Percentage \\
\hline $\mathrm{SiO}_{2}$ & 52 \\
$\mathrm{Al}_{2} \mathrm{O}_{3}$ & 26 \\
$\mathrm{Fe}_{2} \mathrm{O}_{3}$ & 5 \\
$\mathrm{CaO}$ (Lime) & 10 \\
$\mathrm{MgO}$ & 4 \\
$\mathrm{SO}_{3}$ & 3 \\
\hline
\end{tabular}

\subsection{Composite preparation and testing}

Liquid metallurgy route was employed to synthesis the hybrid composites with varied content of hybrid reinforcements. Aluminum 7075 alloy was melted in electrical resistance furnace at a temperature of $760^{\circ} \mathrm{C}$. Vortex was made in liquid aluminum and blended with the assistance of mechanical stirrer. Premixed powder of mica (2 wt. \%), fly ash (1 wt. \%) and red mud (1 wt. \%) particles were included to vortex gradually while mixing was proceeded. Before blending mica, fly ash and red mud particles were preheated in a heater to a temperature of $200^{\circ} \mathrm{C}$ for one hour to remove the moisture content from the reinforcement particles which will enhance the wettability. The metallic dies were equipped by spraying the mold cavity with lubricant. The lubricant was sprayed on the die to control the temperature and also to facilitate the easy removal of the casting. The dies were then closed and molten metal is injected into the dies under high pressure; between 10 and $175 \mathrm{MPa}$. Once the mold cavity is filled, the pressure was maintained until the casting solidifies. Cast Al7075 alloy and its hybrid composites were machined to the standard dimensions and subjected to microstructure and wear studies. Microstructure studies were carried out on metallographically polished samples of cast alloy and hybrid composites using computerized metallurgical microscope. Further, Al7075 alloy with 4 wt. \% of mica with 3 wt. \% of fly ash and 1 wt. \% of red mud, Al7075 alloy with 6 wt. \% of mica$5 \mathrm{wt}$. \% of fly ash and $1 \mathrm{wt}$ \% of red mud composites were prepared by using similar method. Table 5 is indicating the various composites prepared for the study.

Table 5. Various composites prepared for the study

\begin{tabular}{llllll}
\hline SL No. & Code & Matrix & Mica (wt. \%) & Fly Ash (wt. \%) & Red Mud (wt. \%) \\
\hline 1 & A & Al7075 Alloy & 0 & 0 & 0 \\
2 & B & Al7075 & 2 & 1 & 1 \\
3 & C & Al7075 & 4 & 3 & 1 \\
4 & D & Al7075 & 6 & 5 & 1 \\
\hline
\end{tabular}

After the casting the specimen is prepared for the microstructural study using optical microscope to know the uniform distribution of reinforcement particulates in the Al7075 alloy. Microstructure images are taken for Al7075 alloy and for Al7075 with mica, fly ash and red mud particulates reinforced composites. The specimen dimensions for microstructure is $15 \mathrm{~mm}$ in diameter and $5 \mathrm{~mm}$ in height. The specimen surface is grinded by 300,600 and 1000 grit paper. Next the surface is polished by $3 \mu \mathrm{m}$ thickness polishing paper for further smooth finish on polishing machine. After this the specimens are cleaned by distilled water to remove foreign particles like dirt and any other impurities if so present on the polished surface. To achieve a contrast surface the specimens are etched by Keller's reagent.

The wear test specimens of diameter $8 \mathrm{~mm}$ and $25 \mathrm{~mm}$ length were machined from the cast composites for friction and wear test as per ASTM G99 standard ${ }^{(17)}$. The counter face disc used was EN32 steel of $160 \mathrm{~mm}$ diameter and $8 \mathrm{~mm}$ thickness with a hardness value of HRC65. Load was varied from $20 \mathrm{~N}$ to $100 \mathrm{~N}$ in the steps of $20 \mathrm{~N}$ and sliding velocities were varied from 


\subsection{4 to $1.57 \mathrm{~m} / \mathrm{s}$.}

\section{Results and Discussion}

\subsection{Microstructural studies}

Figure 2 (a-b) indicates SEM micrographs of Al7075 alloy (Figure 2a) and Al7075 alloy with 6 wt. \% of mica-5 wt. \% of fly ash and $1 \mathrm{wt}$. \% of red mud (Figure $2 \mathrm{~b}$ ) particles reinforced hybrid composite. It can be seen from images that, the distribution of all the reinforcements is moderately uniform. All the reinforcements are seen at the grain boundaries and inside the grains of Al7075 alloy as in Figure 2a.

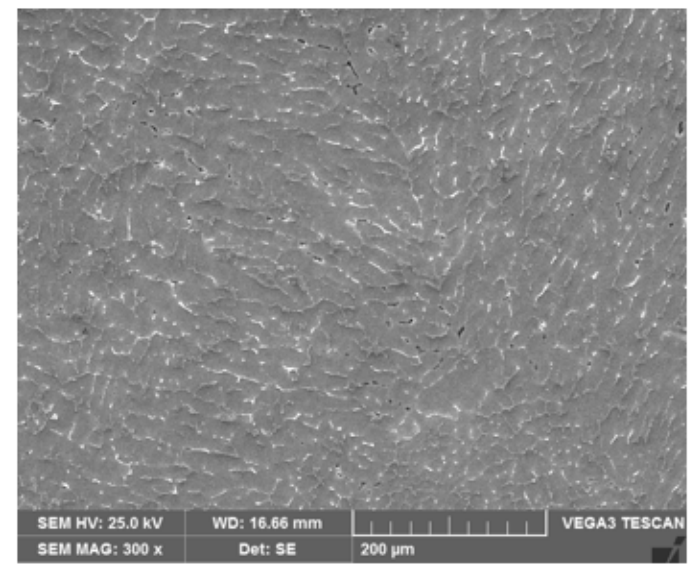

(a)

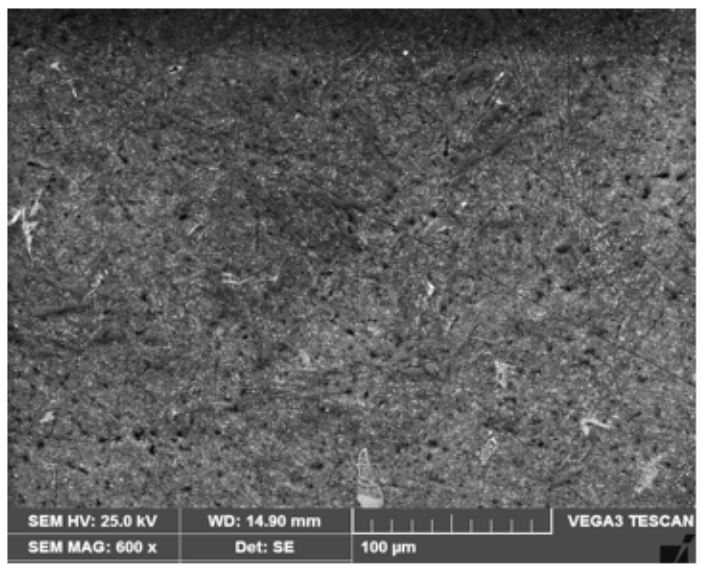

(b)

Fig 2. SEM micrographs of (a) As cast Al7075 alloy (b) Al7075-6 \% Mica with 5\% wt. \% Fly ash and 1\% Red mud composites

Further, here exist magnificent metallurgical bond amongst matrix alloy and reinforcements. Further, it is clearly seen from all the micrographs that there is no visible porosity or cracks in any of the composites demonstrating quality of the composites. A good dispersion is occurred in all the combinations studied and no clustering of reinforcements are seen in the Al7075 alloy hybrid composites as in Figure 2b. SEM micrograph shows there is good bonding between matrix material and the reinforcements. Also, it is clearly evidenced that the particulates are concentrated on the boundary region. Reinforced particles are present without voids and discontinuities. It is very clear that grain size decreases with increase of reinforcement content increases in base matrix.

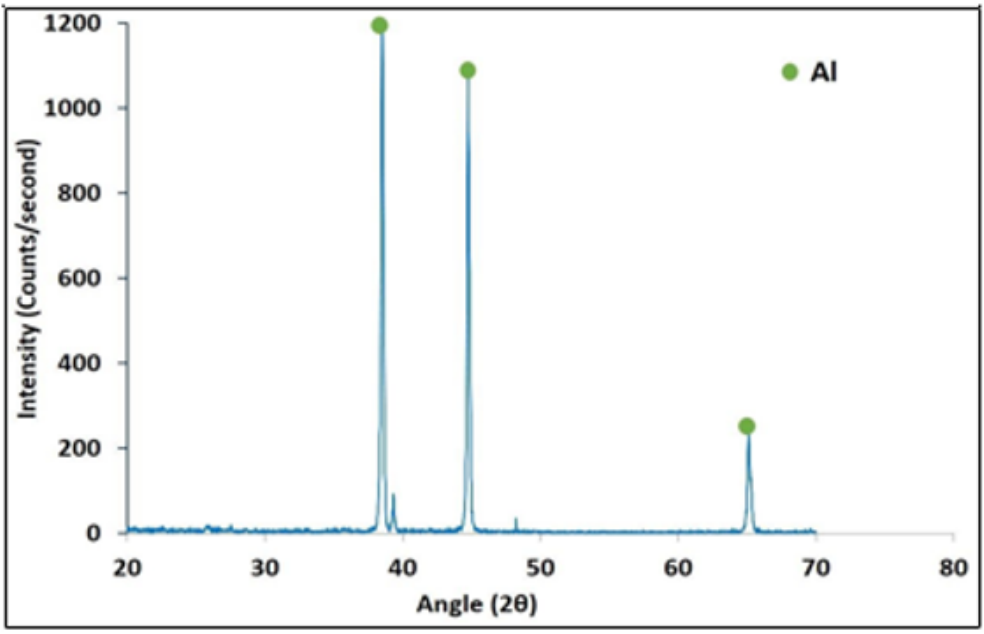

(a) 


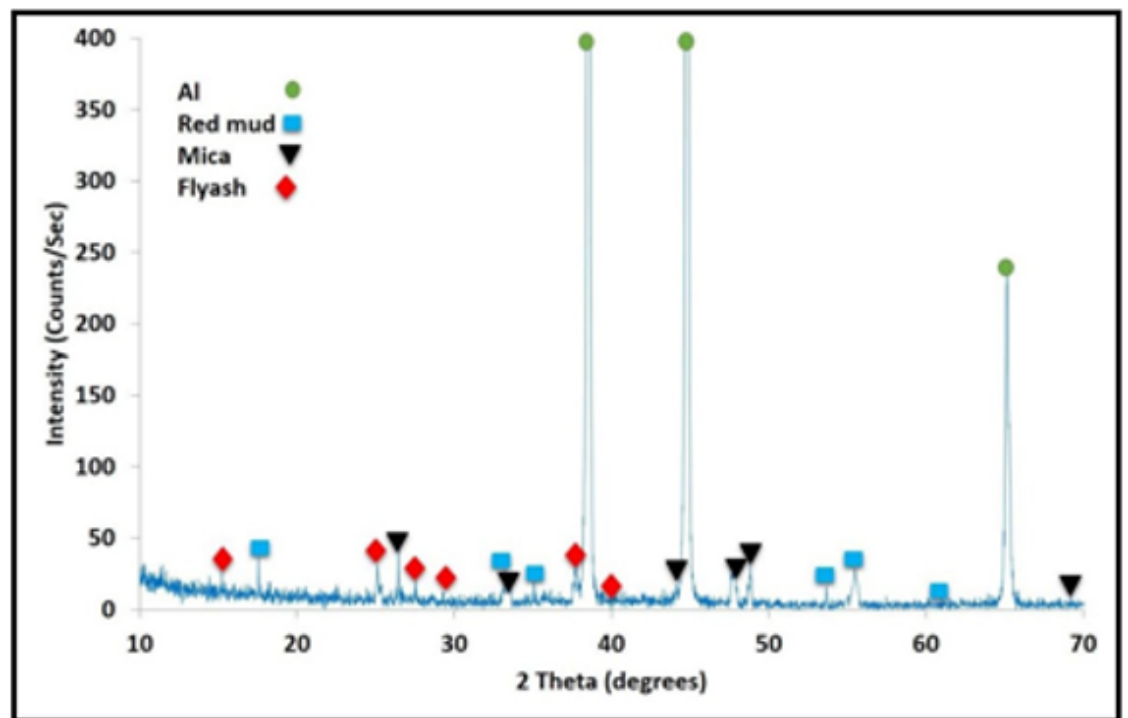

(b)

Fig 3. X-ray Diffraction patterns of (a) as cast Al7075 alloy (b) Al7075-6 \% Mica - 3\% Fly ash-1\% Red mud hybrid composites

X-ray diffraction analysis of Al7075 alloy and its hybrid composite was taken to study the composition and formation of any new phases after casting. Figure 3 (a) shows XRD pattern for Al7075 alloy which shows only peaks related to $\mathrm{Al}$ at $2 \theta$ angles of $38.4^{\circ}, 45^{\circ}$ and $64.6^{\circ}$. The peaks observed at this $2 \theta$ corresponds to $\left(\begin{array}{lll}1 & 1 & 1\end{array}\right),\left(\begin{array}{lll}2 & 0 & 0\end{array}\right)$ and $\left(\begin{array}{lll}2 & 2 & 0\end{array}\right)$ planes of FCC aluminium. Figure 3(b) is the XRD pattern of Al7075 with mica, fly ash and red mud particles reinforced hybrid composites. Al phase is observed at $2 \theta$ angles of $38.4^{\circ}, 45^{\circ}$ and $64.6^{\circ}$. Further, the presence of mica is confirmed at $2 \theta$ angles of $26^{\circ}, 34^{\circ}, 44^{\circ}$ and $49^{\circ}$, the presence of fly ash phases are at $2 \theta$ angles of $15^{\circ}, 34^{\circ}, 28^{\circ}, 29^{\circ}$ and $40^{\circ}$ and the presence of red mud phases are at $2 \theta$ angles of $17^{\circ}, 25^{\circ}, 34^{\circ}, 36^{\circ}, 55^{\circ}$ and $61^{\circ}$.

\subsection{Wear and Friction}

2D Graph 2

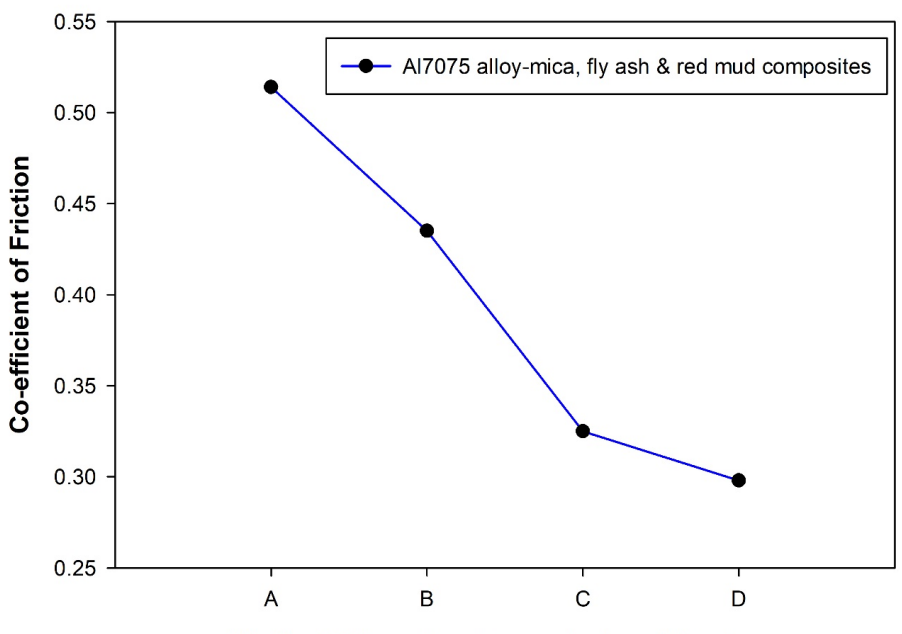

Wt. \% of Mica, Fly ash and Red mud Particles

Fig 4. Co-efficient of friction of Al7075 alloy with mica, fly ash and red mud hybrid composites 
Figure 4 is representing the co-efficient of friction (COF) of Al7075 alloy with mica, fly ash and red mud hybrid composites. The composites of Al7075 alloy with constant $1 \mathrm{wt}$. \% of red mud and varying weight percentages of fly ash and mica are represented in the plot. In the plot along X axis at A represents as cast Al7075 alloy. In the plot along X axis at B represents composites with 2 wt. \% of mica, 1 wt. \% of fly ash and 1 wt. \% of red mud in the Al7075 alloy. Similarly, at C represents composites with 4 wt. \% of mica, 3 wt. \% of fly ash and 1 wt. \% of red mud in the Al7075 alloy and finally D represents composites with 6 wt. \% of mica, 5 wt. \% of fly ash and 1 wt. \% of red mud hybrid composites.

The hybrid composites with increase in mica and fly ash content exhibited less co-efficient of friction as compared to Al7075 alloy with only $1 \mathrm{wt}$. \% of red mud composites as in point A along X axis. The co-efficient of friction of Al7075 alloy- $1 \mathrm{wt}$. \% of red mud composites is 0.514 ; this is reduced as weight percentages of mica increases from 0 to 6 wt. \% in steps of 2 wt. \% and fly ash percentage from 1 to 5 wt. \% in Al7075 alloy. Al7075 alloy with 2 wt. \% of mica, 1 wt. \% of fly ash and 1 wt. \% of red mud composites shown a co-efficient of friction of 0.435 , similarly, Al7075 alloy- 4 wt. \% mica-3 wt. \% fly ash-1 wt. \% red mud hybrid composites are having 0.325 co-efficient of friction. The lowest COF is obtained in the case of Al7075 alloy-6 wt. \% mica-5 wt. $\%$ fly ash-1 wt. \% red mud hybrid composites with 0.298 values. Here important point to be noted is that with the increase in reinforcement content the COF values of hybrid composites decreases when compared to Al7075 alloy, which is mainly due to formation of mechanically mixed layer (MML). This layer which is lubricating in nature is formed due to smearing of fly ash particles along with RM and mica. With lubricating being developed at the contact interface the COF values are found to be decreasing ${ }^{(18,19)}$.

Wear behavior of Al7075 alloy with mica, fly ash and red mud composites are studied with constant load of $100 \mathrm{~N}$ and 1.625 $\mathrm{m} / \mathrm{sec}$ sliding velocity. The wear losses of all the samples are expressed in wear rate. The wear rate of Al7075 alloy with 1 wt. $\%$ of red mud is $55 \times 10^{-3} \mathrm{~mm}^{3} / \mathrm{m}$, there is decrement in the wear loss with the addition of mica and fly ash particles in the Al7075 alloy along with constant 1 wt. \% of red mud particles. The Al7075 alloy hybrid composites with 2 wt. \% mica, 1 wt. \% fly ash and $1 \mathrm{wt}$. \% red mud composites indicated wear rate of $52.1 \times 10^{-3} \mathrm{~mm}^{3} / \mathrm{m}$, Al7075 alloy hybrid composites with 4 wt. \% mica, 3 wt. \% fly ash and $1 \mathrm{wt}$. \% red mud composites indicated wear rate of $44.1 \times 10^{-3} \mathrm{~mm}^{3} / \mathrm{m}$. Further, the lowest wear rate is observed in the case of Al7075 alloy with 6 wt. \% mica, 5 wt. \% fly ash and 1 wt. \% red mud composites with $31.8 \times 10^{-3} \mathrm{~mm}^{3} / \mathrm{m}$. Hence, as the weight percentage of mica and fly ash increases, there is decrease in the wear rate of Al7075 alloy composites. These results are similar to Basavarajappa et al. ${ }^{(20)}$ who studied the wear behavior of 15 wt. \% of SiC reinforced Al2219 and 15 wt. \% SiC and 3 wt. \% of graphite reinforced Al2219 alloy composites. The results revealed that the increasing sliding speed increases the wear rate in the Al2219 alloy and SiC-Graphite composites also. The increased wear as increased speed is due to increased degree of sub surface deformation in the $\mathrm{Al}$ alloy and composites. Further, the wear rate is less in $15 \mathrm{wt}$. \% of SiC and 3 wt. \% of graphite composites due to formation of tribo-layer by the graphite particles.

\section{D Graph 2}

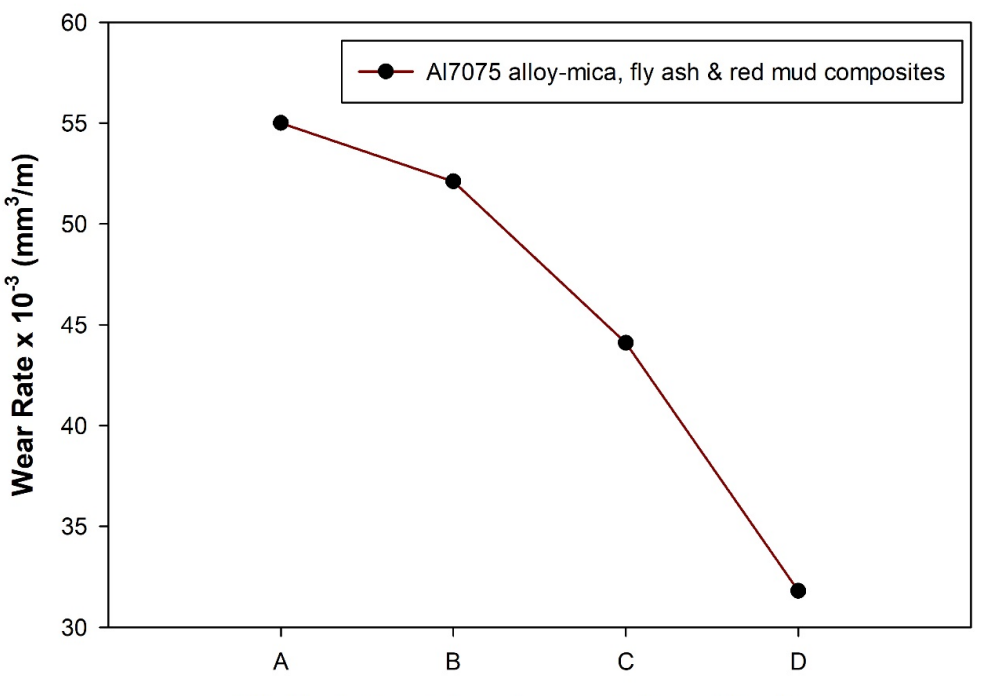

Wt. \% of Mica, Fly ash and Red mud Particles

Fig 5. Wear rate of Al7075 alloy with mica, fly ash and red mud hybrid composites 
It can be presumed that increase in mica and fly ash content had significant positive effect on wear resistance for hybrid composites. Here important point to be noted is that with the increase in reinforcement content the wear rate values of hybrid composites decreases when compared to Al7075 alloy, which is mainly due to high hardness and formation of mechanically mixed layer (MML). The addition of reinforcements in the soft matrix acts as the barrier for the deformation during the wear process.

It's significant to study the worn-out surface morphology of Al7075 alloy and its micro composites as it shows the type of wear the materials with different composition have undergone. During sliding the Al7075 matrix is softer than the rubbing disk material and hence shows viscous flow in Al7075 matrix, which is in the form of pin causing plastic deformation of the specimen surface, resulting in very high material loss. The worn surface of Al7075 alloy shows presence of grooves, micro-pits and fractured oxide layer as shown in Figure 6 (a), which would have caused the increase of wear loss. Whereas 6 wt. \% of mica, 5 wt. \% fly ash and 1 wt. \% of red mud particles in Al7075 alloy composites restrict the viscous flow of the matrix as shown in Figure 6(b), it is observed that the grooves or erosion have reduced with increase in mica and fly ash particles along with red mud means there is more and more resistance to wear loss of Al7075 alloy ${ }^{(21,22)}$. Meanwhile, the stress seems to be transferred on these particles and strain concentration occurs around mica, fly ash and red mud particles and worn surface area shows less and less cracks and grooves with increasing mica and fly ash particles.

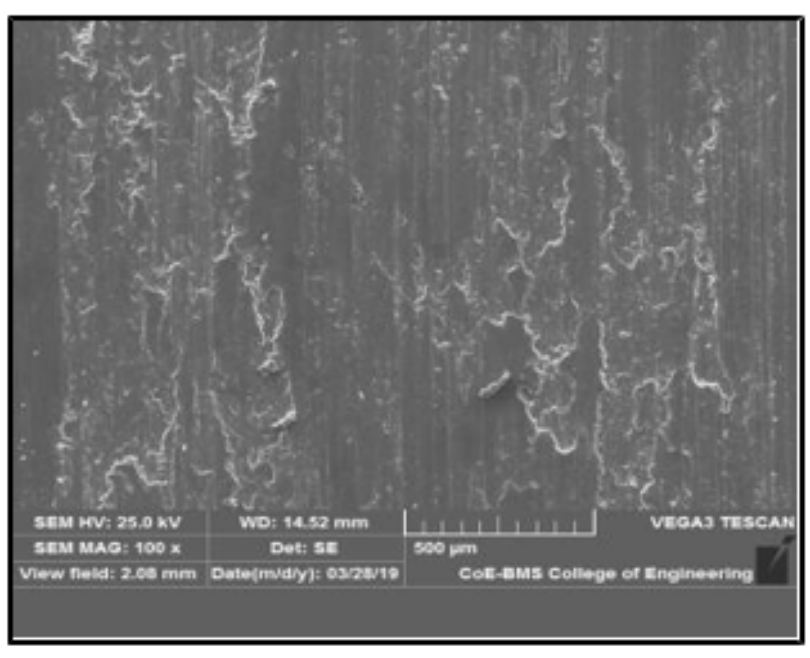

(a)

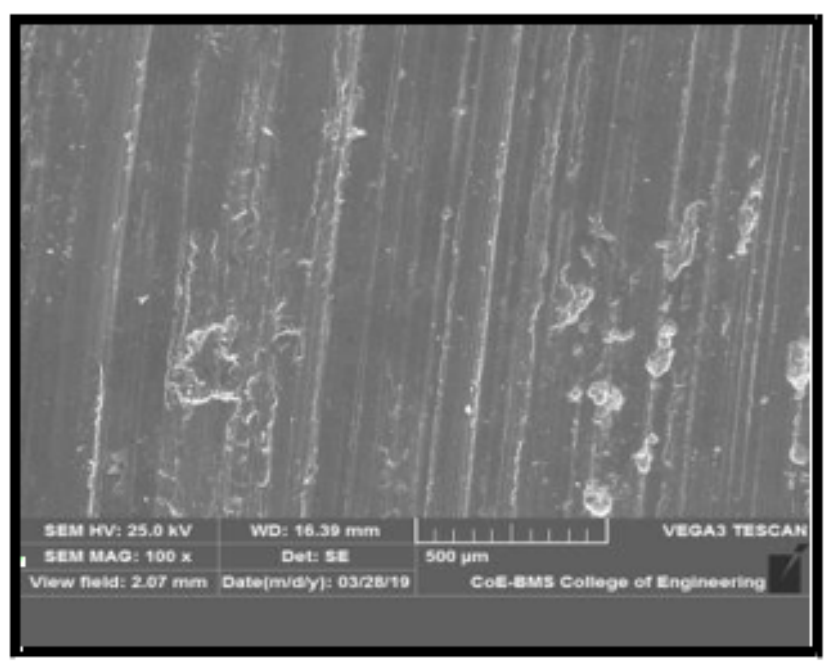

(b)

Fig 6. Worn surfaces SEM micrographs of (a) As cast Al7075 alloy(b) Al7075 alloy with 6 wt. \% mica, 5 wt. \% fly ash and 1 wt. \% red mud composites

\section{Conclusions}

Al7075 alloy with constant 1 wt. \% of red mud and varying weight percentages of mica and fly ash particles reinforced hybrid composites have been manufactured by stir casting. The microstructure and wear practices of Al7075 alloy composites were analyzed. SEM microphotographs revealed the uniform distribution of mica, fly ash and red mud particles in the Al7075 alloy base matrix. The XRD patterns revealed the presence of mica, fly ash and red mud phases in the Al7075 alloy matrix. The addition of mica, fly ash and red mud particles improved the wear resistance of Al7075 alloy. The hybrid composites with 6 wt. $\%$ of mica, 5 wt. \% fly ash and 1 wt. \% red mud particles showed less co-efficient of friction as compared to all other hybrid composites. As mica and fly ash content increases in the Al7075 alloy with $1 \mathrm{wt}$ \% of red mud particles, the wear rate of Al7075 alloy decreased. The worn surface morphologies indicate the various wear mechanisms involved in the hybrid composites. 


\section{References}

1) Chandrashekar A, Ajaykumar BS, Reddappa HN. Mechanical, Structural and Corrosion behaviour of AlMg4.5/Nano Al 2 O 3 Metal Matrix Composites. Materials Today: Proceedings. 2018;5(1):2811-2817. Available from: https://dx.doi.org/10.1016/j.matpr.2018.01.069.

2) Orhadahwe TA, Ajide OO, Adeleke AA, Ikubanni PP. A review on primary synthesis and secondary treatment of aluminium matrix composites. Arab Journal of Basic and Applied Sciences. 2020;27(1):389-405. Available from: https://dx.doi.org/10.1080/25765299.2020.1830529.

3) Nagaral M, Auradi V, Kori SA, Hiremath V. Investigations on mechanical and wear behavior of nano Al2O3 particulates reinforced AA7475 alloy composites. Journal of Mechanical Engineering and Sciences. 2019;13(1):4623-4635. Available from: https://dx.doi.org/10.15282/jmes.13.1.2019.19.0389.

4) Dixon JJJ, Logasarathy, Mageshwaran G, Neveen. M, Fabrication of Al7075 Metal Matrix Composite Through Stir Casting Method - A Review. In: and others, editor. ETEDM - 2019 Conference Proceedings;vol. 7 of 6. .

5) Bharath V, Auradi V, Nagaral M, Boppana SB. Experimental Investigations on Mechanical and Wear Behaviour of 2014Al-Al2O3 Composites. Journal of Bio- and Tribo-Corrosion. 2020;6(2). Available from: https://dx.doi.org/10.1007/s40735-020-00341-2.

6) Bharath V, Auradi V, Nagaral M. Influence of alumina percentage on microstructure, mechanical and wear behaviour of 2014 aluminium alumina metal matrix composites. Jurnal Tribologi. 2020;p. 29-44.

7) Devanathan R, Ravikumar J, Boopathi S, Selvam DC, Anicia SA. Influence of mechanical properties of stir cast aluminium hybrid metal composite with silicon carbide, fly ash and coconut coir ash reinforcement. Materials Today Proceedings. 2020;22:3136-3144.

8) Nagaral M, Kalgudi S, Auradi V, Kori SA. Mechanical Characterization of Ceramic Nano B4C- Al2618 Alloy Composites Synthesized by Semi Solid State Processing. Transactions of the Indian Ceramic Society. 2018;77(3):146-149. Available from: https://dx.doi.org/10.1080/0371750x.2018.1506363.

9) Ravindran P, Manisekar K, Narayanasamy P, Selvakumar N, Narayanasamy R. Application of factorial techniques to study the wear of Al hybrid composites with graphite addition. Materials \& Design. 2012;39:42-54. Available from: https://dx.doi.org/10.1016/j.matdes.2012.02.013.

10) Baradeswaran A, A. Elaya Perumal, Study on mechanical and wear properties of Al7075-Al2O3-graphite hybrid composites. Composites Part B. 2014;56:464-471.

11) Mahdavi S, Akhlaghi F. Effect of the SiC particle size on the dry sliding wear behavior of SiC and SiC-Gr-reinforced Al6061 composites. Journal of Materials Science. 2011;46(24):7883-7894. Available from: https://dx.doi.org/10.1007/s10853-011-5776-1.

12) Hiremath A, Murthy AA, Pranavathmaja SV, Jajodia A, Sreenath R. Effect of end chills, reinforcement content and carburization on the hardness of LM25-borosilicate glass particulate composite. Journal of Mechanical Engineering and Sciences. 2018;12(4):4203-4215. Available from: https://dx.doi.org/ 10.15282/jmes.12.4.2018.16.0362.

13) Seelan RKJ, Rajesh, Pugazhendhi. Mechanical properties evaluation of aluminium LM25-titanium diboride metal matrix composites". International Journal of Applied Engineering Research. 2015;10(8):6414-6418.

14) Umanath K, Selvamani ST, Palanikumar K, Raphael T, Prashanth K. Effect of sliding distance on dry sliding wear behavior of Al6061-SiC-Al2O3 hybrid composite. In: and others, editor. Proceedings of International Conference on Advances in Mechanical Engineering. 2013;p. 749-775.

15) Singh N, Belokar RM, Walia RS. Critical Review on Advanced Reinforcements and Base Materials on Hybrid Metal Matrix Composites. Silicon. 2020. Available from: https://doi.org/10.1007/s12633-020-00853-z.

16) Singh N, Belokar RM. Tribological behavior of aluminum and magnesium-based hybrid metal matrix composites: A state-of-art review. Materials Today: Proceedings. 2020. Available from: https://dx.doi.org/10.1016/j.matpr.2020.09.757.

17) Nagaral M, Auradi V, Kori SA. Dry Sliding Wear Behavior of Graphite Particulate Reinforced Al6061 Alloy Composite Materials. Applied Mechanics and Materials. 2014;592-594:170-174. Available from: https://dx.doi.org/10.4028/www.scientific.net/amm.592-594.170.

18) Harti JI, Prasad TB, Nagaral M, Jadhav P, Auradi V. Microstructure and Dry Sliding Wear Behaviour of Al2219-TiC Composites. Materials Today: Proceedings. 2017;4(10):11004-11009. Available from: https://dx.doi.org/10.1016/j.matpr.2017.08.058.

19) Attar S, Nagaral M, Reddappa H, Auradi V. Effect B4C particulates addition on wear properties of Al7025 alloy composites. American Journal of Materials Science. 2015;5(3C):53-57. Available from: https://doi.org/10.5923/c.materials.201502.05.

20) Basavarajappa S, Chandramohan G, Mahadevan A, Thangavelu M, Subramanian R, Gopalakrishnan P. Influence of sliding speed on the dry sliding wear behaviour and the subsurface deformation on hybrid metal matrix composite. Wear. 2007;262:1007-1012. Available from: https://dx.doi.org/10.1016/j. wear.2006.10.016.

21) Sutar H, Roy D, Mishra SC, Murmu RR. Sliding Wear Performance Evaluation of Red Mud (RM), RM + Fly Ash (FA) and RM + FA + Al Coatings on Mild Steel. Materials Sciences and Applications. 2016;07(03):171-179. Available from: https://dx.doi.org/10.4236/msa.2016.73017.

22) Nagaral M, Auradi V, Kori SA, Hiremath V. Investigations on mechanical and wear behavior of nano Al2O3 particulates reinforced AA7475 alloy composites. Journal of Mechanical Engineering and Sciences. 2019;13(1):4623-4635. Available from: https://dx.doi.org/10.15282/jmes.13.1.2019.19.0389. doi:10.15282/jmes.13.1.2019.19.0389. 